\title{
What's Good for the Goose is Bad for the Gander: Negative Political Advertising, Partisanship, and Turnout
}

\author{
Daniel Stevens University of Exeter \\ John Sullivan University of Minnesota \\ Barbara Allen Carleton College \\ Dean Alger Independent scholar
}

\begin{abstract}
This study examines citizens' perceptions of fairness and legitimacy in political advertising. Using focus groups, an original national survey, and data on election 2000, as well as drawing on results from a replication of the national survey in 2004, we characterize political ads from the citizen's perspective. We then turn to the impact of "negative" advertising on voter turnout. Like several studies, we find circumstances under which turnout can be increased by negative ad criticisms. However, we show that this general result is only part of the story. Drawing on research in political psychology, we suggest that voters are "motivated processors" of advertising claims; as such, they evaluate the fairness of an ad according to their partisan predispositions. We show that when partisans perceive the criticisms of their own party's candidate to be fair, they are less likely to say they will vote. As a result, we find that negative advertising not only may affect the total turnout in an election but also has an important and varying impact on the composition of the electorate.
\end{abstract}

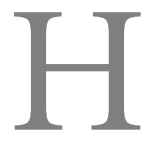
ow does "negative" campaign advertising affect the American electorate? In recent years the impact of negative ads has been the subject of a great debate fueled by diverse methodologies and equally diverse answers. Political scientists and pundits have been especially alarmed by suggestions that negative ads may affect partisans and independents differently, depressing turnout for the latter, while stimulating turnout of the former. Concerns about the influence of political advertising, including misgivings about the increase and impact of negative campaign ads, are a subset of two more general issues confronting the American polity: worries about declining participation in elections and the prospect of an increasingly polarized electorate. Given perceptions of the high stakes and close contests of the 2000 and 2004 presidential elections, the precise composition of the electorate at the polls is also of critical interest. Our research offers new evidence about how voters characterize "negative" or "attack" ads and, in light of these characterizations, how negative ads affect electoral participation, polariza- tion, and composition. We demonstrate that voters' partisanship substantially colors perceptions of legitimate negativity in advertising and that these characterizations in turn affect who goes to the polls. As a consequence, some negative advertising campaigns may stimulate while others depress overall turnout, but more than the total turnout is at stake. Negative advertising also affects the composition of the electorate since partisans and independents experience an advertising stimulus (or deterrent) differently.

Electoral campaigns are increasingly "going negative" as Geer (2006), among others, has documented. In the decade since Ansolabehere and Iyengar (1995) published findings showing that negative advertising depressed voter turnout, especially among Independents, other scholars have criticized their methodology (Bartels 1996; Brooks 2006) and reported different effects. Finkel and Geer (1998) found no evidence of demobilization of Independents from negative ads. Lau and Pomper $(2000,2001)$ found that effects on Independents varied with the amount of negative advertising exposure: Independents who were exposed 
to a campaign which contained a moderate amount of negative ads showed no statistically significant evidence of such an influence, but exposure to high levels of negative advertising - negativism above 90\% (an amount that was higher than their actual campaign observation) —was significantly related to a decline in predicted voter turnout for Independents. Among partisans, their work showed, higher levels of ad negativity were associated with an increase in predicted turnout.

Several studies have concentrated on refining the classification of ads rather than focusing singly on the effect "negative" ads may have on partisans and independents. Johnson-Cartee and Copeland (1991), Bartels and Vavreck (2000), and Kahn and Kenney (1999) have demonstrated voters' ability to distinguish "negative" ads, whose exceptionally harsh style or tone, distortion of facts, or use of personal attacks seem to cross the line, from "contrast" ads that offer a legitimate critique of an opponent's policy stands, qualifications, or other substantive information. [0]Similarly, Sigelman and Kugler (2003) showed considerable variance in citizens' perceptions of the tone of campaigns. Freedman and Lawton (2000) demonstrated that Independents viewed unfair charges from one candidate, followed by similar responses from the opponent, as particularly objectionable. Following these advances, Jamieson (2000) examined the different effects produced by "attack" and "contrast" ads on overall predicted turnout. She [0] reported not only a decrease in predicted turnout associated with exposure to highly negative attack ads but also a reduction in the sponsoring candidate's vote share (Jamieson 2000, 112). However, her work also showed that contrast ads, even when critical of an opponent, increase both turnout and the sponsoring candidate's vote share. Geer (2006) and Goldstein and Freedman (2002a, 2002b) similarly demonstrated that ads with negative information about an opponent can inform voters and stimulate turnout among partisans, while Geer also found that such "negative" ads can be a relatively good source of campaign information. Taken together, studies distinguishing either among advertising types or between partisans and independents demonstrate the importance of classifying ads more carefully as a first step in evaluating their differential effects on a segment of the electorate.

Such findings have refined conventional wisdom about the general relationship between partisans and campaign communications articulated by Kahn and Kenny: "People with strong connections to the political world participate in elections, regardless of the tenor of campaigns" ... [they are] "unaffected by the negativity of campaigns" $(1999,885,887)$. Identifiers with a major party, who may be assumed to have greater interest and knowledge of politics, are thus seen as being more certain about their intentions to vote and vote choices - and to tolerate the cross current of campaign criticism to a greater extent. Kahn and Kenny also found that Independents, who may have less interest and knowledge about politics, are more likely to vote as the proportion of critical information in the candidates' ads increases-but only if they view the criticism as reasonable. Voters are capable of making such distinctions, and if reasonable criticism is presented in a stimulating way, Independents may also respond with an increased intention to vote. But they find that turnout declines when "uncivil and inappropriate mudslinging” occurs (Kahn and Kenney 1999).

Goldstein and Freedman have summarized the state of research on this topic: "despite the substantial attention the subject has drawn, there is still considerable debate as to how, to what extent, and under what conditions advertising matters" (2002b, 24), suggesting that we must "look more closely at how ads are perceived by actual voters" (2002a, 736). We took this charge seriously. We examine citizens' distinctions between fair and unfair charges raised in election ad campaigns, asking how these perceptions relate to partisanship and, ultimately, how they influence vote intentions. We go beyond studies of negative advertising that do not distinguish among responses of partisan subgroups to show that citizens do differentiate types of negativity and that partisans' characterizations of "negativity" are driven less by the content than the source of an ad. Partisans apply generous bounds of fairness to charges from their own candidate but are highly sensitive to criticism leveled at their candidate. The effects on voting are thus more complex than previous research has allowed. ${ }^{1}$

\section{Theory}

Work in social and political psychology (e.g., Fischle 2000; Goren 2002; Sherif and Sherif 1967) suggests that partisans are motivated information processors

\footnotetext{
${ }^{1}$ Sigelman and Kugler (2003) also examine how ordinary citizens perceive advertising. Our findings and approach differ in three important ways: (1) our focus on the perceived legitimacy as well as the tone of ads, (2) our finding that partisans, who are less likely to characterize a given ad as "negative," apply their criteria of fairness to evaluations of ads asymmetrically, and (3) by considering the potential effects of perceptions of advertising on vote intention.
} 
who exhibit predictable biases in managing information. Strong beliefs often lead to biased memory searches, biased choice of inferential heuristics, and a predisposition to judge arguments supporting existing beliefs to be accurate and to discount contrary arguments (Kunda 1999; Lodge and Taber 2000; Redlawsk 2002).

More recent research by Westen et al. (2006) at Emory University used functional magnetic resonance imaging (fMRI) technology to show that when partisans were presented with information threatening their beliefs about their preferred candidate or an opposition candidate, they reached biased conclusions, with the fMRI showing their effort to reach an "emotionally stable judgment" through confirmation bias to have involved primarily the part of the brain associated with processing emotions. The region of the brain that involves reasoning remained quiescent. The fMRI also showed that once these biased conclusions were in place, the region of the brain associated with reward or relief was activated, suggesting that motivated judgments are doubly reinforcing, rewarding the return to emotional equilibrium while also avoiding the emotionally averse information. The authors note that various methods of escaping from aversive information, including threats to one's beliefs about a candidate for political office (e.g., through denial, rationalization, and motivated distortion) have been associated with dopamine release.

Despite the obvious power of motivated information processing by partisans, however, people's capacity to believe what they want to believe is "constrained by their ability to construct seemingly reasonable justifications for these conclusions;" there is a "trade-off between one's desire to know the truth and the desire to arrive at conclusions that sit comfortably with one's prior beliefs" (Fischle 2000, 137-38; Kunda 1990, 480). Willful ignorance may not always bring bliss.

The latter insight fits well with recent theoretical work on affective components in political choice (Brader 2006; Marcus, Neuman, and MacKuen 2000). This research suggests that partisans usually regard criticisms of an opponent by a candidate they support as expected and confirmatory-and they are unlikely to scrutinize such claims closely. Criticisms of a partisan's own candidate can prompt two very different responses, however. Usually, they will be seen as routine and expected, resulting in a reliance on partisan habit and the rejection of the claim. But if criticism of a partisan's candidate arouses anxiety because the criticism is seen as fair and legitimate or because the opponent's rhetoric is seen as strikingly unfair, then there is a dramatically different response: "When the threat/surveillance response is activated we find a close and demonstrable link to higher levels of active calculation, the questioning of existing behavioral patterns" (Neuman et al. 1997, 8). Information that seems to "fit" may be hard to ignore.

How might motivated information processing affect partisan responses to "negative" advertising? We hypothesize that rather than exhibiting a consistently greater tolerance for negative campaign claims, as the literature currently states, partisans will vary in their reactions in distinct and predictable ways; it depends on whether a partisan's own candidate is targeted and whether the claims are seen as fair or not. As a result, partisans' varying responses to negative ad claims will have a differential impact on the level of turnout-and on the composition of the electorate. ${ }^{2}$

\section{Research Design}

We used multiple methods to test our theory. For the first stage of our research we conducted seven 2-hour focus groups, ranging in size from six to 12 subjects, in Minnesota during the 2000 election. Protocols dealt with media coverage of the election, with a special focus on televised campaign ads (see the online appendix at http://journalofpolitics.org/articles. html). We asked subjects to talk about how they experienced campaign advertising as they viewed negative or "oppositional," positive or "advocacy," and contrast/comparative ads (Bartels and Vavreck 2000; Jamieson 2000; Lau and Pomper 2001) taken from the presidential, U.S. Senate, and House races that aired in Minnesota in 2000. The focus groups offered an in-depth view of citizens' responses and provided a foundation for the national survey we subsequently conducted. Comments by subjects in two focus groups sum up well a principal response on the fairness issue, illustrating our main theoretical points and presaging a central finding from our survey. In an October 18 group, a respondent, Margit, commented on a harshly negative ad from

\footnotetext{
${ }^{2}$ This is not equivalent to the truism that "partisans view exchanges through partisan lenses." The truism generally refers only to persuasion and, thus, says nothing about how partisan lenses influence the processing of information from ads and what behavioral effects may follow.
} 
a U.S. Senate race in Minnesota containing distorted video:

"And you know, I think there's a difference between criticizing someone's record, which I think is perfectly legitimate, and then saying what you yourself would do instead... ; that's legitimate and to me, it's not negative, it's simply scrutinizing the situation. What I resent here is this implication that Mark Dayton is untrustworthy, that there's something flawed about his character. That's when criticizing someone's record becomes negative in a sinister sort of way, and that's when you really attack the person's integrity, honesty...."

An October 11 focus group included this exchange and sequence of comments on other ads from the same source, which clearly illustrate an anxiety response. One comment also illustrates how the "actual voters" Goldstein and Freedman refer to reason from circumstances in their own lives to political judgment:

MARY: "I've been turned off lately by Senator Rod Grams's ads. They're so negative."

DICK: "The thing that's disturbing about his ads is he shows Mark Dayton and sort of distorts how he looks... I mean, not that I agree with Mark Dayton, but I think that's an unfair ad."

JEANNE E.: "Now, in his new one, the people are all green..."

JOHN: "I want to go up and adjust the set."

MARY: "He's been there almost six years; I would think he'd do more of his ads on what he's done."

DICK: "It's causing me to reconsider him. I'm sort of for Grams, but I don't know if I want to vote for him." DUANE: "It tends to make me reconsider. In the business I'm in, when we get together, if somebody has something they want to add, to work towards a problem, that's useful. But for somebody to sit there and tear a project down, but not give their positive opinion or how they're going to do it, that doesn't help anybody. So that ad does nothing for me - except change my opinion about Grams."

Although focus group methodology does not allow statistical generalization, the data derived from the group discussion offer deeper insight into issues, enabling us to see how citizens can articulate rich, nuanced perspectives about ad communications. Such enhanced understandings of what citizens think may be used to inform survey questions that provide data for statistical analysis. The detailed characterizations of ads by our focus group subjects represented responses to video and verbal stimuli from congressional as well as presidential spots, suggesting that their evaluations and classifications of ads may transcend a particular electoral context. When we later presented our survey subjects with the text of specific charges from campaign ads, we found that by simulating the stimulus materials used in the focus groups we obtained similarly detailed responses from our survey respondents. As a result, we can report correspondingly rich responses from our survey respondents and gain the benefits of generalizable survey data.

After identifying patterns in the discussions of the focus group participants, we entered the second stage of our research in which we distilled the comments and language from the groups into survey questions to be asked of a national sample. The principal survey for the purposes of this paper was conducted by telephone from 9 March to 22 June 2002 on a random sample of 705 voting age citizens nationwide (see the online appendix). The online appendix illustrates that the sample we obtained was similar to the national population in terms of marital status, sex, and race, while, like most telephone surveys, slightly underrepresenting less educated and younger individuals. We also compare turnout and partisanship in our sample to another random large sample survey of individuals from the 2000 election, the American National Election Survey (ANES). Again, we see only minor differences. ${ }^{3}$

The survey instrument consisted of two main sections. Initially, we gauged respondents' general thoughts and feelings about political advertising, based on their level of agreement with statements taken almost verbatim from the focus groups. We also used an open-ended question format to learn, in the respondents' own words, what makes a political ad positive and what makes a political ad negative. Our goal was to assess the role of partisanship in responses to political advertising while controlling for broader perceptions and attitudes toward campaign ads. To the extent that these perceptions and attitudes are themselves influenced by partisanship, our analysis is a conservative gauge of the totality of partisan effects.

In the second part of our survey we looked in detail at perceptions of fairness and partisanship. We began by replicating the questions used by Freedman and Lawton (2000), asking whether it is fair or unfair for candidates to criticize an opponent in campaign ads that address various issue positions, matters of character, and other candidate constructs. To limit respondent fatigue we restricted these questions to five topics, randomly ordered, rather than the twelve that Freedman and Lawton used. For the sake of comparability we not only covered issue- and character-based charges, but also made sure to include the topics that

\footnotetext{
${ }^{3}$ As with ANES surveys, more respondents claim to have voted than in the population.
} 
had produced wide variation in perceptions of fairness in the Freedman and Lawton study.

By referring to criticisms of "candidates" in the abstract, our questions at this stage adopted the approach of previous research, albeit with a national rather than a state (Freedman and Lawton 2000) or regional (Johnson-Cartee and Copeland 1989) sample. To gauge the role of partisanship in the next stage of questioning, we injected partisanship into candidates' criticisms by providing some specific examples of these same criticisms of the opponent made by the presidential candidates and their supporters during the 2000 election. We also randomized the order in which we asked these questions. We did not inform respondents that they were specific examples of the same charges whose fairness they had previously been asked to assess.

\section{Results}

Our respondents' perceptions of an ad's fairness varied dramatically according to the type of criticism and partisanship (see the online appendix). As in previous studies, perceptions divided neatly along two dimensions with issue-based criticism appraised as much fairer than criticism about a candidate's personal life. Beyond confirming earlier findings, however, we asked how perceptions of fairness offered in response to hypothetical criticism compared to voters' evaluations of actual ad claims. In real campaigns, identifiable candidates of known partisanship aim criticisms at an often equally known opponent with a different partisan affiliation. Even when the sponsorship of an ad is obscured, its target generally is not. Charges made in the context of an election may be expected to convey meanings that are not at all abstract for a voter.

To move beyond assessments of criticisms-inthe-abstract, we asked respondents about the fairness of specific charges from the George W. Bush and $\mathrm{Al}$ Gore campaigns in the 2000 presidential election. These criticisms were taken directly from each candidate's advertising or from newspaper stories during the election (see the online appendix). ${ }^{4}$ We made the

\footnotetext{
${ }^{4}$ Newspaper stories, from which we drew examples of personal criticism, did not necessarily involve explicit criticism by the opponent. For example, the Gore campaign made no explicit mention of Bush's daughters' underage drinking. Interviewers in our survey recorded comments made by respondents during the survey; none questioned whether these were criticisms that had actually been leveled by the candidates in 2000. Excluding perceptions of these criticisms from our analysis makes no difference to the results.
}

specific charges as parallel as possible. Thus, the example of "criticizing an opponent for taking contributions from special interests," referred to a charge that Gore made about Bush's ties to big oil and to a claim that Bush had made about Gore being beholden to trial lawyers. Claims concerning "criticizing the behavior of an opponent's family members" referred to underage drinking by the candidate's daughter(s). ${ }^{5}$

Substituting an actual campaign claim for a hypothetical criticism produced a dramatic change, a finding that emerged for issue-based as well as character-centered criticisms (see the online appendix). For example, more than one-third of respondents switched from believing some of the issue-based charges were fair (unfair) in the abstract to saying that specific charges were unfair (fair). Why do voters' perceptions of the fairness of an ad depend on whether they are asked to evaluate a claim about a hypothetical candidate or an actual criticism leveled against a real candidate during a specific campaign? The conventional wisdom suggests that partisanship is not the answer, based on findings that voters exhibiting an affinity for politics, including identification with either major party, tolerate negative advertising, at least when it comes to ads evaluated in the abstract. We theorize, in contrast, that in an actual campaign, partisanship will color perceptions of the fairness of an advertising claim and that the effects of the resulting evaluations of an ad's fairness are more complex than the conventional wisdom holds. To test our theory that partisanship influences perceptions we ran a series of logit models comparing the variables that affected perceptions in the abstract to those driving perceptions of the specific examples, including all of the variables that Freedman and Lawton[0] and Johnson-Cartee and Copeland indicate are important influences. In addition, we then examined the claim that partisans are aloof to the effects of their evaluations of advertising, that they will vote regardless.

Following the literature, the explanatory variables consisted of six main groups. First, we controlled for the impact of general attitudes toward political advertising, using data from our survey to examine whether simply having a distaste (or liking) for political advertising drives perceptions of fairness more than partisanship.

\footnotetext{
${ }^{5}$ When our respondents were surveyed, George W. Bush's job approval was above $70 \%$ in CNN/Gallup and USA Today polls. It was also high in our sample, at $83 \%$, although there were large differences between Democrats and Republicans. Such high approval could have affected our results if respondents deemed criticism of Bush generally unfair. We found no effects of this kind.
} 
We included variables that measure "positive thoughts and feelings" and "negative thoughts and feelings about political advertising" based on the extent of our respondents' agreement with a series of statements regarding thoughts and feelings about political advertising ${ }^{6}$ (the online appendix shows these and all other measures.) We also added a dummy variable based on answers to an open-ended question about how respondents define negative advertising. Unlike positive advertising, where definitions ranged widely, $55 \%$ of our sample spontaneously defined negative advertising very simply, as criticizing an opponent. ${ }^{7}$ If there is an association between believing an ad is negative and deeming it to be unfair, respondents who defined negative advertising in this way as mere critique should be more likely to have viewed the examples of criticism in our survey as unfair.

Second, we examined indicators of "views of government" because, beyond attacking specific candidates, the undercurrent of much negative advertising is cynicism about government (Ansolabehere and Iyengar 1995). Citizens who view government positively may also perceive the kinds of charges that are the common currency of negative political advertising to be among the most unfair. Our indicators of views of government were perceptions of external efficacy and trust in the federal government. The third group of variables captured individual differences in political expertise, measured by political knowledge and, because readers of newspapers tend to be more politically engaged (Chang and Krosnick 2003), by frequency of newspaper readership. We hypothesized that political expertise fosters greater tolerance of negative advertising, meaning that voters with more expertise should be generally more likely to see criticism as fair (Kahn and Kenney 1999). Fourth, we included measures of media use, paying particular attention to local news viewership because most political advertising airs during local news (Freedman, Franz, and Goldstein 2004). We controlled for variance in exposure to political advertising and for the possibility that consumption of local news sensitizes citizens to campaign criticism (Allen et al. 2007). The fifth category of variables encompassed key psychological and demographic variables related to political behavior and perception: approval of President Bush, generational cohort, sex, and race

${ }^{6}$ Principal components factor analysis, with an oblique rotation, of the responses to these statements indicated these two, positive and negative, factors.

${ }^{7}$ For $63 \%$ of respondents, this was also the full extent of their definition.
(Miller and Shanks 1996). ${ }^{8}$ Finally, in the sixth category, we included dummy variables for party identification (for Republicans and Independents), with Democratic identifiers as the reference variable (coded from the standard ANES question format) to gauge the influence of partisanship.

If identifying with a major party leads to a higher threshold for what constitutes fair, relevant, and legitimate criticism in advertising, we should see a consistently lower tolerance for criticism among Independents relative to their partisan peers for both abstract and specific criticisms. If partisans engage in motivated processing when evaluating such criticisms, however, we should find that their perceptions of claims made about an actual candidate differ from their views of criticism described hypothetically. We do not expect partisanship to affect perceptions of fairness in the abstract; we do anticipate differences in the way Democrats and Republicans evaluate the fairness of the specific criticisms leveled against George W. Bush and Al Gore in actual campaign ads. The coefficient on the Republican dummy variable should therefore be negative and statistically significant when the criticism refers to Bush and positive and statistically significant for criticisms of Gore.

All variables were coded from zero to one in order to ease interpretation. In Table 1 we display the results for the key variables of interest. ${ }^{9}$ In general our models indicate that perceptions of fairness in advertising are idiosyncratic, particularly when the charges therein are personal. The fit of some of the models is weak. They tend to explain much more of the variance in perceptions for issue-related charges than for personally directed charges (where there is also less variance to explain). We briefly comment first on key variables other than partisanship.

Political knowledge is consistently important to perceptions in the abstract, and also has some effect on perceptions of specific criticisms, particularly for those charges that are unrelated to a candidate's personal life. Indeed, political knowledge behaves as conventional wisdom indicates identifying with a major party might: citizens who know more about politics have a greater tendency to perceive negative

\footnotetext{
${ }^{8} \mathrm{We}$ tested several plausible relationships between age and perceptions of fairness. Specifying the effect of age in years as linear in our models produced a mixture of statistically significant findings that were difficult to interpret. Adding a quadratic term for age in years did not help. We theorized that perhaps we were capturing generational effects. With the dummy variables for generations shown in Table 1 the relationship became clearer. These definitions were taken from Bennett and Bennett (1990).

${ }^{9}$ Full results are available from the authors upon request.
} 


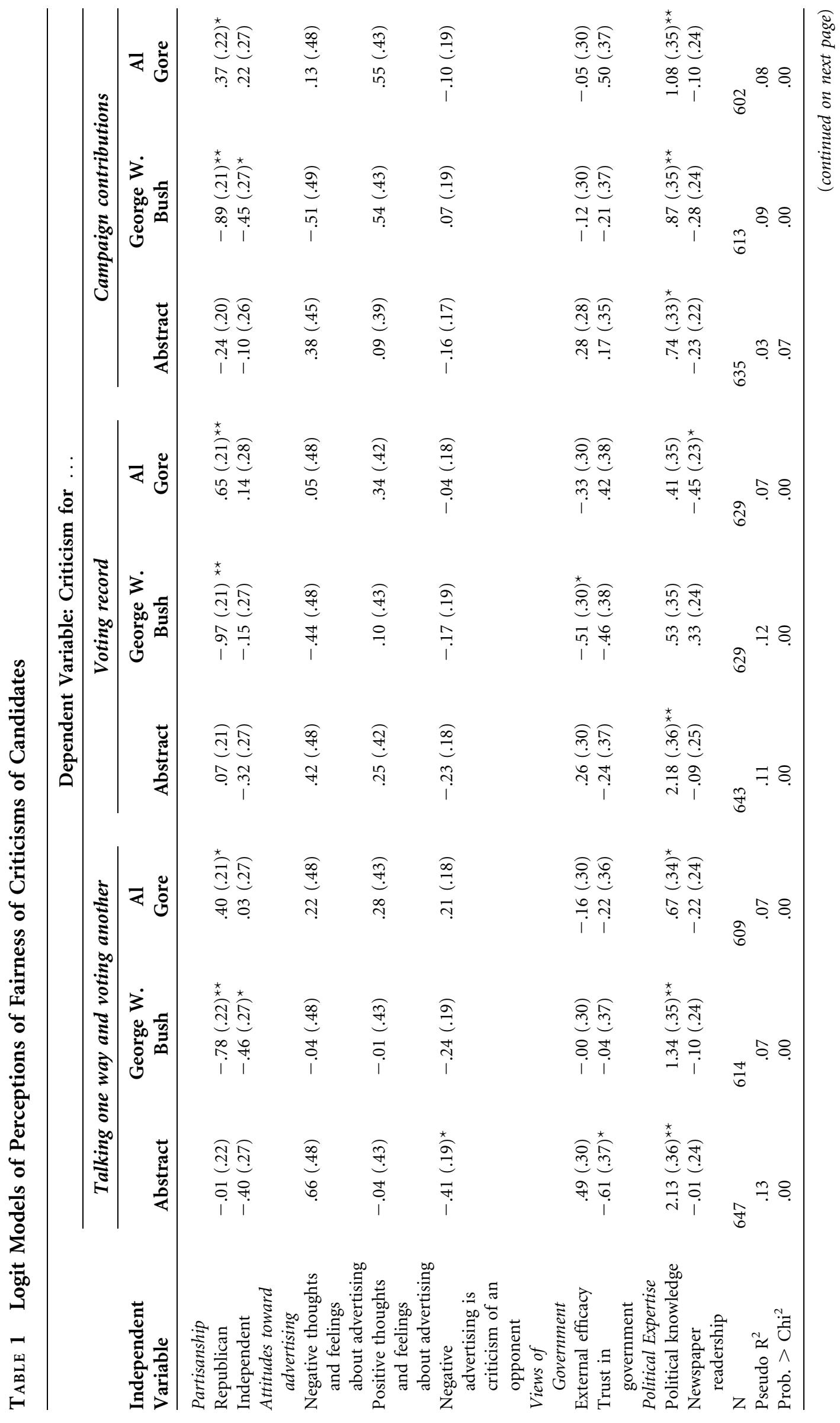




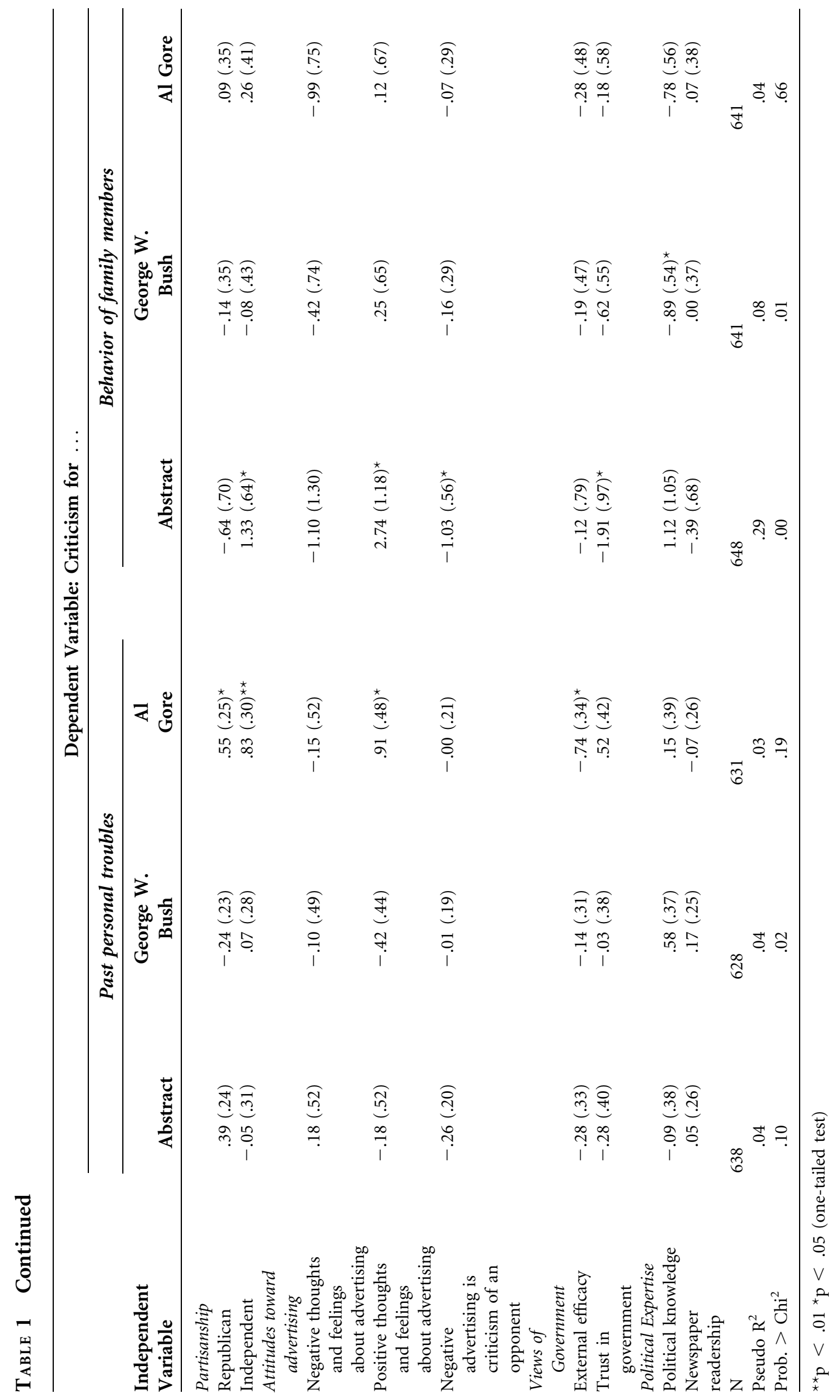


charges as fair. Such a finding suggests that a greater understanding or familiarity with politics results in more allowance for the roughness of politics. As a corollary one may expect those most likely to see criticism of candidates as illegitimate or unfair to be the least engaged with politics. Yet we see no effect of this kind when engagement is represented by newspaper readership. Several other potential relationships also do not emerge. The three indicators of attitudes toward political advertising failed to influence perceptions of fairness. Similarly, trust in government, which was a factor in two of the models for which the charges were presented to the respondents in the abstract, had no effect when the charges were leveled at George W. Bush and Al Gore. Likewise external efficacy failed to have an impact. In short, views of government have scant influence on assessments of a particular ad's legitimacy. ${ }^{10}$ Thus the most consistent influence on perceptions of fairness in advertising, in terms of statistical significance and direction, is political knowledge. This result echoes previous findings (Ansolabehere and Iyengar 1995; Freedman and Lawton 2000; Kahn and Kenney 1999): all else equal, political expertise is associated with a more generous standard of what constitutes fair criticism of a candidate. But what of partisanship?

The results in Table 1 confirm our theory that the relationship between partisanship and perceptions of fairness is robust and contingent on the party of the candidate. ${ }^{11}$ Unlike political knowledge, partisanship is not consistently more likely to result in viewing the criticisms of advertising as fair; partisans, even controlling for political knowledge, do not display higher thresholds in their judgments of fairness. When the criticism is about Bush, Republican identifiers are consistently less likely to judge it as fair than Democratic identifiers; if the charges relate to Gore, Repub-

\footnotetext{
${ }^{10} \mathrm{We}$ also found few effects for our measure of exposure to political advertising. We checked the robustness of this finding using our 2004 data for which, unlike our earlier survey, we knew the television market in which each respondent resided. Using CMAG data for 2004 on presidential advertising in each respondent's market we ran models of perceptions of fairness with exposure to advertising as an independent variable operationalized in a variety of ways. In each series of models, the influence of exposure to advertising was overwhelmingly statistically insignificant. In short, perceptions of fairness in advertising do not appear to be contingent on exposure.

${ }^{11}$ We specified the models based on our reading of the most important variables in the literature, but we also checked the robustness of the results by adding variables for internal efficacy, education, length of residence in the community, living in the South, living in a border state, and income (variables in Rosenstone and Hansen's (1993) model of turnout in presidential elections). They have a negligible impact on the size and statistical significance of the effects of partisanship.
}

licans are more likely to view them as fair and legitimate than Democrats. In only one instance did partisanship fail to affect the evaluation of an actual ad claim; criticism of a candidate's family members universally crossed the line. ${ }^{12,13}$ As predicted, partisanship has no impact on perceptions of fairness in the abstract, but is crucial to understanding voters' perceptions of actual ads.

Figure 1 provides illustrative simulations for "criticizing an opponent for talking one way and voting another," and for "criticizing an opponent for taking campaign contributions from certain special interests," first taken in the abstract, followed by the specific cases of Bush or Gore. The figure shows the probability of seeing a charge as legitimate in each case. All variables in the model are set at their mean (or mode for categorical variables) while party identification is allowed to vary.

Figure 1 clearly demonstrates the effects of partisanship and is indicative of active, motivated processing of the advertising claims by partisans. For example, when the charge is "talking one way and voting another," Independents are least likely to see the criticism as legitimate when it is stated in the abstract. Yet when respondents are presented with specific examples of such charges from the 2000 presidential election, the relative position of partisan groupings changes. Republicans become the least likely to view this criticism of President Bush as legitimate and Democrats the most likely, while Republicans are the most likely to call the criticism fair when it is of Al Gore, with Democrats becoming the least likely to say criticism of Gore is fair. For the issue of taking campaign contributions from special interests the patterns are similar.

Conclusions about the effects of negative advertising based only on perceptions of fairness in the abstract must be reconsidered. The evaluations of criticisms against a hypothetical candidate, which may be made on the basis of principles of fairness, do not translate into standards applied universally when the identities of candidates are known. When

\footnotetext{
${ }^{12}$ Our theory implies that strong partisans may be especially prone to "motivated processing." To replicate previous research in the field (and in view of our sample size), we specify partisanship in three broad categories. In additional analysis, we separated respondents into strong, weak, and leaning partisans, finding that strong partisans are likely to see criticism of their own candidate as particularly unfair and of claims against his opponent as particularly fair.

${ }^{13}$ We use one-tailed tests in Table 1 because our hypotheses regarding partisanship are directional. With two-tailed tests, four of the eleven statistically significant coefficients in Table 1 would have $\mathrm{p}$ values greater than .05 but less than .10 .
} 


\section{Figure 1 Variation in Perceptions of Fairness of "Criticizing an Opponent for Talking One Way and Voting Another" By Partisanship}

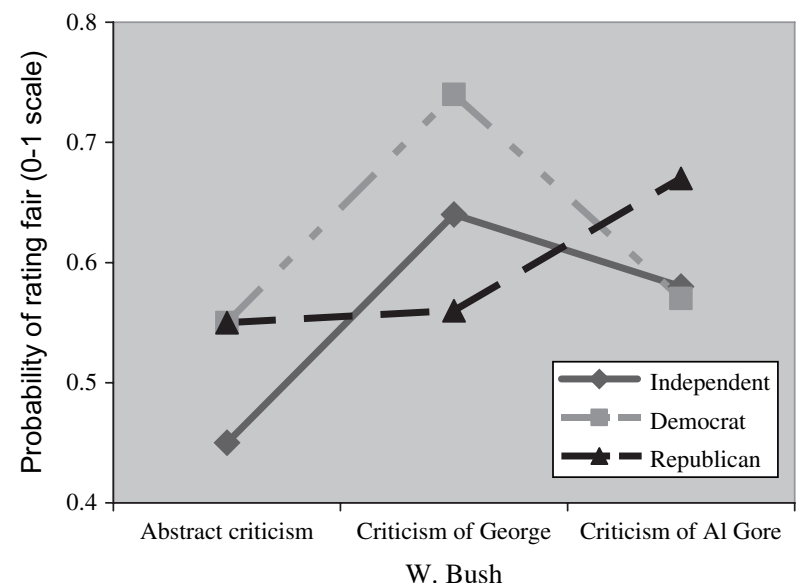

Variation in Perceptions of Fairness of "Criticizing an Opponent for Taking Campaign Contributions from Certain Special Interests” By Partisanship

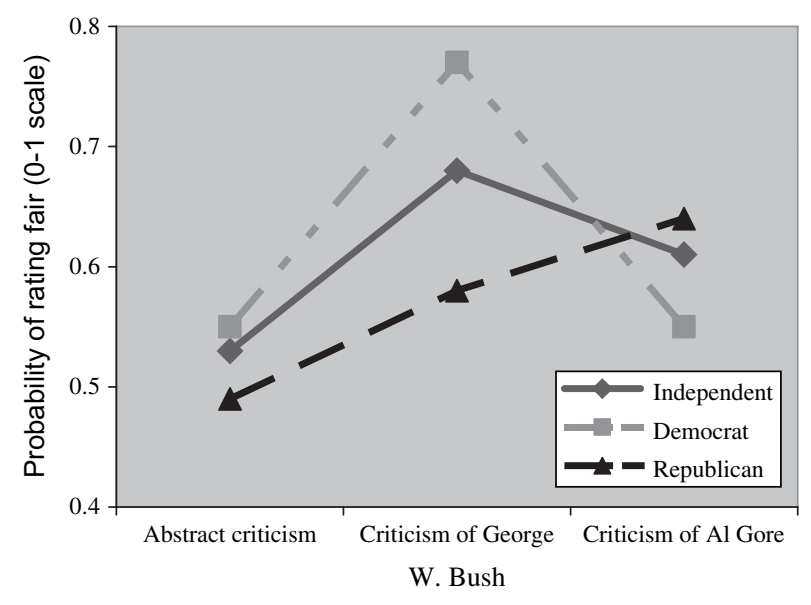

specified candidates are the objects of evaluation, information processing based on principles of fairness gives way to processing and evaluations motivated by partisanship. While political knowledge is generally associated with more generous standards of legitimacy in abstract and specific examples, antecedent partisan loyalties substantially colored perceptions of the fairness of the specific charges against George W. Bush and Al Gore. Standards of fairness are not immutable principles that are even-handedly applied. Partisans, regardless of political acumen, do not apply more generous standards of fairness to ad claims, but instead apply whatever standards they hold asymmetrically.

Consistent with a theory of motivated processing, partisans' perceptions of fairness are contingent on the party that a candidate represents. How do perceptions of fairness in political advertising affect turnout? Although the timing of our survey limits the inferences we may make (it took place more than a year after the 2000 election), we can examine the relationship between perceptions of fairness in our sample and reported turnout. In addition, we replicated the survey in October 2004 (i.e., during the 2004 election campaign), with reference to candidates George W. Bush and John Kerry, obtaining results that were substantively the same, further supporting our findings related to Election 2000. Where appropriate, we discuss the results in this article. (For details of the survey and the relationship between fairness and turnout, see the online appendix.)

Turning to the data pertaining to the 2000 election, we note that respondents' recall of their behavior may be inaccurate. To check how faulty their recollections might have been we looked at the ANES panel surveys from 1956 to 1960 and from 1972 to 1976 . Respondents were asked whether they had voted four years earlier. A total of roughly $10 \%$ of respondents in each panel misreported their behavior. That $90 \%$ of respondents seem able to recall correctly whether they had voted four years earlier allayed our concern that the relationships we sought to examine could be confounded by faulty recall of voting behavior from 15 to 18 months earlier. ${ }^{14}$

To examine hypotheses suggested by findings that perceptions of fairness of advertising mediate the individual propensity to vote and that partisans are less affected than Independents by mudslinging and unfairness (Freedman and Lawton 2000; Kahn and Kenney 1999), we model an individual's probability of having voted in 2000 as a function of his or her attitudes toward advertising, perceptions of fairness in advertising, and partisanship. We control for political knowledge, gauging the effects of the attitudes and perceptions of interest independently of this highly influential variable. If partisanship moderates how perceptions of ad fairness affect turnout, making partisans less responsive to variation in perceptions of fairness, we would expect no differences between Republicans and Democrats, and a significantly reduced impact of perceptions of fairness on partisans compared to Independents. However, if partisans are motivated processors, predisposed to judge charges against their own candidate as unfair, then the more they consider the charges against their candidate to be fair, the less likely they should be to vote. This hypothesis implies that partisan turnout is more

\footnotetext{
${ }^{14}$ The ANES panels do not preclude the possibility that reported voting behavior at the time of the first survey is inaccurate but we have no way of gauging this conjecture, and there is more error in recalling for whom one voted than whether or not one voted.
} 


\section{TABLE 2 Logit Model of the Relationship Between Perceptions of Fairness and Turnout}

\section{Independent Variable}

Negative thoughts and feelings about advertising

Positive thoughts and feelings about advertising

Negative advertising is criticism of an opponent

Political knowledge

Republican

Independent

Perceptions of fairness of charges against

George W. Bush

Perceptions of fairness of charges against Al Gore

Perceptions of fairness of charges against George

W. Bush x Republican identifier

Perceptions of fairness of charges against Al Gore $\mathrm{x}$

Republican identifier

Perceptions of fairness of charges against George

W. Bush x Independent identifier

Perceptions of fairness of charges against Al Gore $\mathrm{x}$ Independent identifier

Constant

$\mathrm{N}$

Pseudo $\mathrm{R}^{2}$

Prob. $>\mathrm{Chi}^{2}$
$.75(.56)$

$.37(.52)$

$.13(.22)$

$2.09(.40)^{\star *}$

$.54(.62)$

$-.60(.61)$

$1.75(1.03)^{\star}$

$-2.77(1.17)^{\star *}$

$-5.62(1.61)^{\star *}$

$4.71(1.74)^{\star *}$

$-2.40(1.85)$

$3.49(1.97)^{\star}$

$-.21(.61)$

638

.11

.00

Wald Tests of the Differences in Coefficients

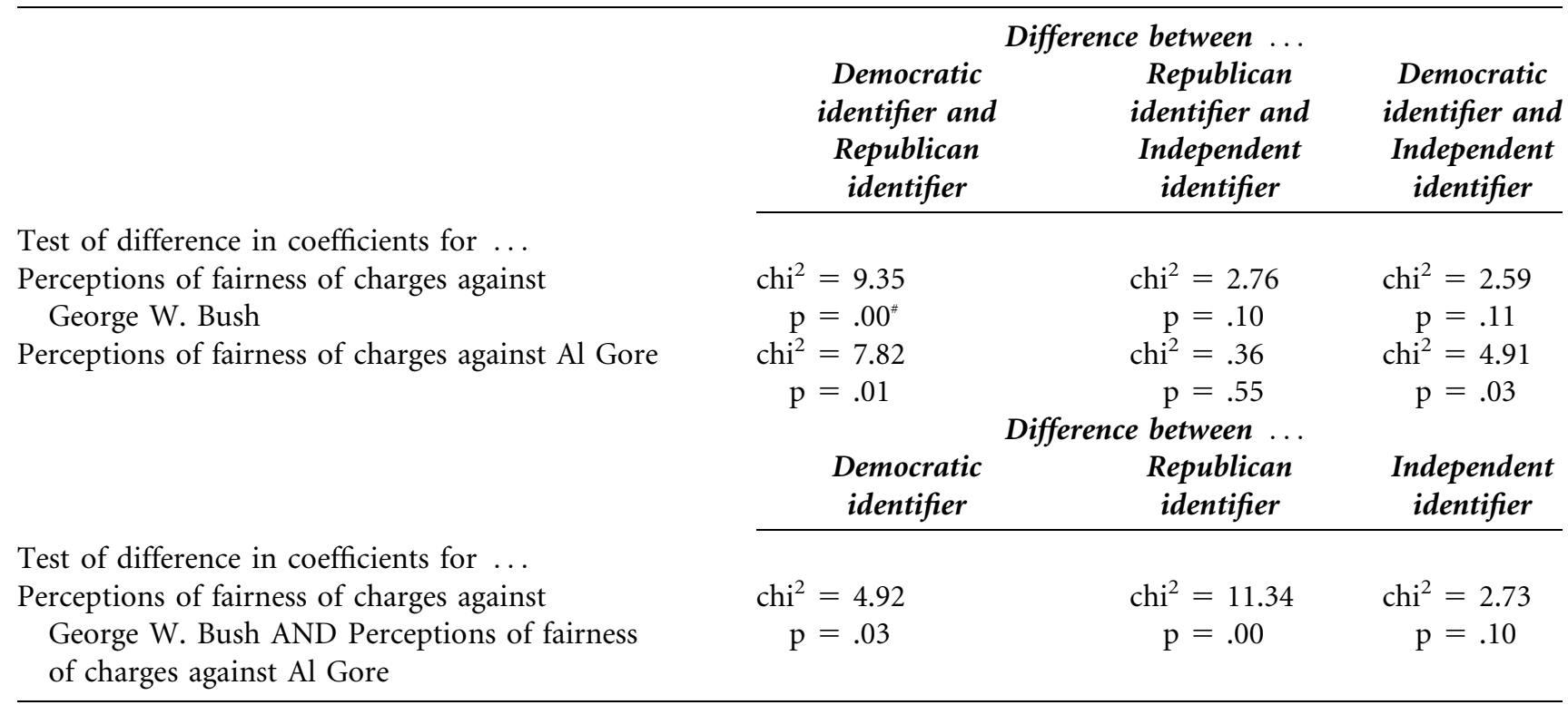

\#All p's for the Wald tests are two-tailed

affected by perceptions of fairness than Independent turnout and that this effect is contingent on which candidate is the subject of an advertising claim.

We test the alternatives in Table 2 . We created two identically operationalized, but separate, indexes of fairness based on respondents' evaluations of the five charges against George W. Bush and Al Gore. We examine our claims regarding greater and asymmet- rical effects for partisans through interactions between each of these indexes and partisan identification, and Wald tests of the differences between these coefficients. ${ }^{15}$ The interaction term, for example

\footnotetext{
${ }^{15} \mathrm{We}$ also examined whether there was an effect of abstract perceptions of fairness, either on its own or as an effect that was moderated by partisanship; we found neither.
} 
Perceptions of fairness of charges against George W. Bush $x$ Republican identifier in Table 2, only shows whether perceptions of fairness of criticism of George W. Bush have a different effect on the turnout of Republican identifiers than on Democrats and Independents; Wald tests show the statistical significance of the difference between Republicans and Democrats and for differences in the effects of perceptions of fairness of criticism of George W. Bush and Al Gore on the turnout of Republicans, Democrats, and Independents, all of which are relevant to our theory.

The coefficients in Table 2 show that perceptions of fairness among partisans have a dramatic effect on reported turnout. The more partisans evaluated the charges against their own candidate as fair, the less likely they were to have voted; the more they evaluated the charges against the opposing candidate as fair the more likely they were to have voted. For Democrats the effects are captured by the variables Perceptions of fairness of charges against George W. Bush and Perceptions of fairness of charges against Al Gore. Wald tests demonstrate that these differences are robust: perceiving charges against $\mathrm{Al}$ Gore as fair has an impact on the turnout of Democrats that is statistically significantly different, and opposite in sign, from the impact such perceptions have on Republicans. The same is true for charges against George W. Bush, with the direction of effects reversed. The relationship between perceiving charges against $\mathrm{Al}$ Gore as fair but not characterizing criticism of George W. Bush as fair is statistically significant for Democratic identifiers and Republican identifiers alike, and the two groups are polarized in their perceptions. Among Independents, as expected, many of the relationships do not reach conventional levels of statistical significance.

The effects shown in Table 2 are also slightly stronger for the candidate of the party with which an individual identifies than for his opponent. The flip side is that perceiving the charges made against one's own candidate as unfair is associated with a boost in the turnout of partisans, while the same perception about the charges made by one's candidate against the opponent is associated with a reduction in the turnout of partisans. Partisans are not less responsive to the tone of advertising than Independents. In fact, they are more so- and the direction of their responsiveness is driven by partisanship.

Figure 2 illustrates these results by simulating the probability of voting among partisans and Independents, given variance in perceptions of the fairness of criticisms of candidates Bush and Gore. The simu-

\section{Figure 2 Simulations of How Perceptions of Fairness Affect Turnout}
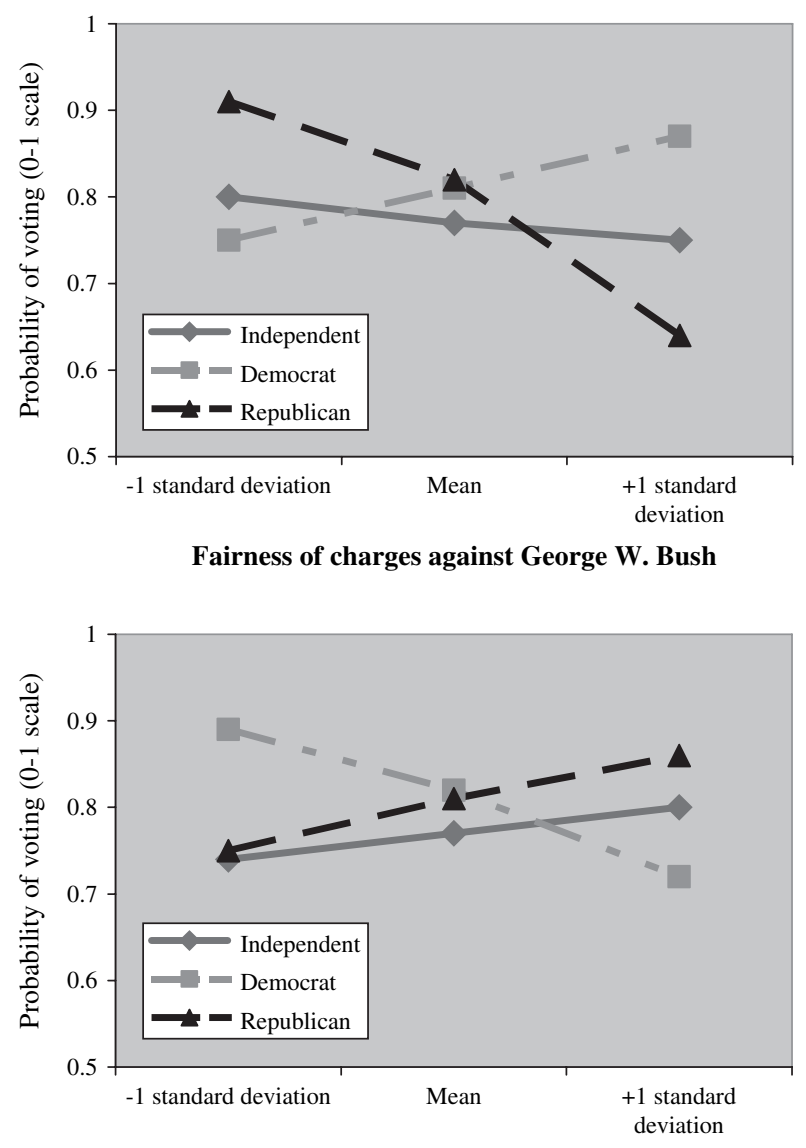

Fairness of charges against Al Gore

lations are based on Table 2, with all other variables set at their mean (or mode for categorical variables). The upper chart holds perceptions of fairness of criticism of Gore at its mean and allows perceptions of fairness of criticism of Bush to vary one standard deviation below or above its mean. The lower chart does the same for Gore, holding perceptions of charges made against Bush at its mean. Figure 2 clearly demonstrates the extent to which partisans are affected by the content that is typical of negative advertising. Whereas the probability of Independents voting is hardly affected by perceptions of fairness (the lines are essentially flat) perceptions of fairness greatly influence propensity to vote as the steep slope of the line shows.

Although ANES panel surveys suggest that recall of whether or not one voted in an election is largely accurate, our findings for turnout may be questioned since the survey took place more than a year after the 2000 election. We therefore replicated the 2002 study 
on a national sample of 720 individuals in October 2004, avoiding the problems of timing and recall. ${ }^{16}$ The examples in 2004 were of criticisms from the George W. Bush and John Kerry campaigns. ${ }^{17}$ The results were substantively very similar (see the online appendix). For example, among Democratic identifiers, the more they perceived the criticisms of George W. Bush to be fair, the more certain they said they were to vote; to the extent that they saw criticism of their own candidate, John Kerry, as fair, however, they reported themselves as being less certain of voting. For Republicans the relationships were reversed. ${ }^{18}$ In 2004, Independents looked even less like motivated processors than they had in the first survey, behaving more consistently with our theory.

Our data do not permit us to assert confidently whether perceptions of fairness and their varying effect on partisans and independents regularly affect turnout. We have demonstrated, however, that, all else equal, partisans are more likely to view charges leveled against their candidate as unfair. In addition, the more often partisans respond habitually by viewing criticism

\footnotetext{
${ }^{16}$ Random digit dialing was used to recruit 510 respondents nationally. We also contacted as many of the respondents from the 2002 survey as possible and were able to interview 210. It makes no difference to the substance of the analysis if we exclude the panel respondents. For more details on this survey, see the online appendix.
}

${ }^{17}$ To reflect the context of the 2004 election, our questions covered some new categories of criticism, and left out a few used in 2002. If we exclude the new categories and create an index of perceptions of fairness based only on the categories used in 2002, the direction and statistical significance of the coefficients as well as the results of the Wald tests are unchanged.

${ }^{18}$ This result begs the question of whether perceptions of message fairness in advertising are merely a proxy for something more general, such as confidence in the candidate. Was Kerry, in other words, a "weak" candidate? Fortunately the 2004 survey contained an experiment that bears on the measure of fairness. We presented one-half of the sample with an example of criticism of John Kerry's service in Vietnam and of criticism of George W. Bush for misleading the nation regarding weapons of mass destruction in Iraq. The other half of the sample was presented with the same criticisms but with the addition of countervailing arguments, for instance that independent organizations rejected the claims about Kerry's Purple Hearts. We found that the additional information had a dramatic effect on partisan perceptions of the fairness of these charges. For example, $67 \%$ of Republican identifiers perceived criticism of Kerry's service in Vietnam as fair in the absence of countervailing information, but only 39\% saw it as fair after receiving additional information. Conversely, Democratic perceptions of this criticism barely shifted. Such change (or stability) says less about perceptions of a given candidate than it signifies about a genuine shift in voters' perceptions of the fairness of a campaign ad claim. Of course, there is almost certainly interplay between advertising campaigns and confidence in a candidate; to the extent that criticism of a candidate resonates with the electorate (perhaps because the candidate fails to counterattack or the media echoes the criticism, giving it legitimacy, as with the 1988 Dukakis campaign), it may undermine confidence in the candidate. of the opposing candidate as legitimate, the more likely they are to be mobilized. Thus in many campaigns, partisans will be mobilized by negative advertising (i.e., Republicans and Democrats will be at the high points of Figure 2). Such an effect only augments the mobilizing force of negative advertising, if indeed such negativity is arresting, anxiety inducing, and informative. Thus, our results suggest a simple process may be at work in which the psychological tendency to view in opposite ways negative claims against a favored candidate and those aimed at an opponent may mobilize partisans selectively.

Although there is a bias against accepting criticism of one's own candidate, we find that when these criticisms do penetrate and seem to fit, they are demobilizing. This result bears out another aspect of motivated processing theory, which argues that a respondent's understanding of reality conditions his or her ability to draw a given conclusion (confirmatory or not) from a given body of information; the confirmation bias of motivated processing is constrained by a respondent's more fundamental conception of "reality" (Kunda 1999). Similarly, attacks by one's own candidate that are perceived as unfair are also demobilizing. Thus in campaigns where one candidate's negative advertising is particularly effective or one candidate's advertising is widely perceived as unfair we may see one set of partisans turning out to vote in higher numbers while another is more likely to stay at home. There may be little net effect of exposure to advertising on turnout, yet the composition of the voting electorate will be altered. Finally, campaigns where partisans from both parties are repelled by the attacks of their candidates or convinced by the attacks of their opponent will see lower turnout among partisans.

A candidate whose advertising campaign was perceived as unfair by his or her own partisans and those of the other party would pay a heavy price, according to these data, demobilizing supporters and mobilizing those of the opponent. (See the focus group comments reported earlier, particularly those of Duane and of Dick, a Grams supporter whose support was called into question by Grams's negative ads.) Of course, most campaigns try to avoid being doubly penalized by alienating their own partisans as well as their opponents' with attacks that both view as unfair; going negative, our data show, can be a high risk strategy with the potential for great costs or benefits, and very little between these extremes. If a candidate can identify a course of attack that his or her own partisans agree is fair and to which the opposition similarly gives credence, however, our 
data suggest that going negative may be a winning strategy. ${ }^{19}$

\section{Conclusion}

The importance of research on ad communications in election campaigns is put in perspective by three facts: (1) Typically, presidential and state-wide campaigns spend the majority of their funds on television ads. (2) Local television news is the prime news source of election information, images, and commentary for the mass public — and the primary site of campaign advertising (Freedman, Franz, and Goldstein 2004). (3) At the nexus of political advertising and local election news coverage, ads often overwhelm news stories in terms of viewer exposure (e.g., Kaplan, Goldstein, and Hale 2005).

We have found that partisanship shapes responses to negative advertising; we argue that conventional wisdom does not have the process quite right. Partisanship does not lead individuals to ignore negative ads, nor does it result in higher thresholds of fairness, leaving partisans unaffected by ad content. Instead, we find strong support for the hypothesis that partisans are motivated processors of information; they respond habitually, according to their partisan bias-but with a crucial exception under an important condition. Partisans are predisposed to see charges against their favored candidate as unfounded, and when confronted with such charges, they are inclined to counter them and vote as expected. If they recognize a charge against their candidate as potentially fair, or if their party's candidate does something that crosses the line into stark mudslinging, however, partisans will question their exist-

\footnotetext{
${ }^{19}$ The specification of our turnout model is designed to obtain a clear look at the effects of fairness, controlling for the key variables in Table 1, such as political knowledge, and also for general attitudes toward advertising. Alternatively, we could include more independent variables, potentially adding multicollinearity and inefficiency to the model estimates, but also shedding some light on the robustness of relationships. In additional analysis we therefore added variables for internal and external efficacy, trust in the federal government, frequency of reading a newspaper, frequency of watching local television news, sex, race, generation, approval of the president, marital status, education, living in a southern state, and living in a border state (as defined by Rosenstone and Hansen 1993). We see some weakening of relationships, most clearly for perceptions of fairness of criticism of $\mathrm{Al}$ Gore on the turnout of Democratic identifiers. Yet the overall picture of statistically significant, distinct effects of perceptions of fair criticism on turnout for the two groups of partisans (depending on the target of criticism), remained.
}

ing voting habits, activating doubts about their preferred candidate. Abandoning a habit may not result in a new preference for the opposing candidate, but it may be enough to cause even an ardent partisan to stay away from the polls. We have demonstrated these effects in two surveys and two election contexts. (See the online appendix for 2004 results.) An important task remains: identifying and analyzing the factors that lead partisans to accept the potential validity of negative charges against their own party's candidate. Understanding why partisans sometimes do not reject information at odds with their beliefs will undoubtedly illuminate the more usual response of rejecting aversive information in processes leading to confirmation bias.

Reflecting on electoral processes broadly, our findings raise questions about the sources of information on which evaluations of an ad's legitimacy may be based. Our data show how negative ads against a partisan's initially preferred candidate that are perceived to be fair may raise demobilizing doubts, resulting in a change in the composition of the voting electorate. Is it also the case that partisans are likely to abandon their default behavioral predispositions when the campaign criticism or behavior arousing the initial anxiety response also seems to be taking hold in the electorate-or is prevalent in the media? Are perceptions of fairness also related to the climate of opinion about the subject of an ad claim, or even an ad itself? What role may election news coverage play in shaping this climate? Research on political advertising effects has considered either the tone of the campaign or the characteristics of campaign news coverage, but seldom expressly tied these two exogenous influences together. It makes sense to think that negative campaign claims may be reinforced (even amplified) or diminished (perhaps dispelled) according to the climate of opinion shaped by such news coverage (e.g., see Pomper 2001, 59, 62). We speculate that news coverage of the presidential candidates may influence whether negative ad claims are deemed to be fair and whether partisans who perceive them as legitimate are ultimately prompted to reconsider their vote or shun the voting booth altogether. Such possibilities also imply that the impact of campaign advertising is not wholly contingent upon exposure, as the Daisy Girl ad taught us more than 40 years ago. Mediated perceptions of ads and ad campaigns among partisans are equally, or, possibly, more consequential than mere exposure. All criticisms are apparently not equal; what is good for the goose may not be good for the gander. 


\section{Acknowledgments}

Thanks to John Geer, Rick Lau, and Justin Wedeking for helpful comments and suggestions.

Manuscript submitted $\mathbf{\square}$

Manuscript accepted for publication $\mathbf{\square}$

\section{References}

Allen, Barbara, Daniel Stevens, Gregory Marfleet, John Sullivan, and Dean Alger. 2007. "Local News and Perceptions of the Rhetoric of Political Advertising." American Politics Research 35 (4): 506-40.

Ansolabehere, Stephen, and Shanto Iyengar. 1995. Going Negative: How Political Advertisements Shrink and Polarize the Electorate. New York: The Free Press.

Bartels, Larry. 1996. "Review of Going Negative, by Stephen Ansolabehere and Shanto Iyengar." Public Opinion Quarterly 60 (3): 456-61.

Bartels, Larry, and Lynn Vavreck, eds. 2000. Campaign Reform: Insights and Evidence. Ann Arbor: University of Michigan Press.

Bennett, Linda, and Stephen Earl Bennett. 1990. Living with Leviathan. Lawrence: University of Kansas Press.

Brader, Ted. 2006. Campaigning for Hearts and Minds: How Emotional Appeals in Political Ads Work. Chicago: University of Chicago Press.

Brooks, Deborah Jordan. 2006. "The Resilient Voter: Moving Toward Closure in the Debate over Negative Campaigning and Turnout." Journal of Politics 68 (3): 684-97.

Chang, LinChiat, and Jon Krosnick. 2003. "Measuring the Frequency of Regular Behaviors: Comparing the "Typical Week' to the 'Past Week."' Sociological Methodology 33 (1): 55-80.

Finkel, Steven, and John Geer. 1998. "A Spot Check: Casting Doubt on the Demobilizing Effect of Attack Advertising." American Journal of Political Science 42 (2): 573-95.

Fischle, Mark. 2000. "Mass Response to the Lewinsky Scandal: Motivated Reasoning or Bayesian Updating?" Political Psychology 21 (1): 135-59.

Freedman, Paul, Michael Franz, and Ken Goldstein. 2004. "Campaign Advertising and Democratic Citizenship." American Journal of Political Science 48 (4): 723-41.

Freedman, Paul, and L. Dale Lawton. 2000. "Campaign Advertising, Perceived Fairness, and Voter Turnout." Presented at the annual meeting of the Midwest Political Science Association.

Geer, John. 2006. In Defense of Negativity: Attack Ads in Presidential Campaigns. Chicago: University of Chicago Press.

Goldstein, Ken, and Paul Freedman. 2002a. "Campaign Advertising and Voter Turnout: New Evidence for a Stimulation Effect." Journal of Politics 64 (3): 721-40.

Goldstein, Ken, and Paul Freedman. 2002b. "Lessons Learned: Campaign Advertising in the 2000 Elections." Political Communication 19 (1): 5-28.
Goren, Paul. 2002. "Character Weakness, Partisan Bias, and Presidential Evaluation." American Journal of Political Science 46 (4): 627-41.

Jamieson, Kathleen Hall. 2000. Everything You Think You Know about Politics ... And Why You're Wrong. New York: Basic Books.

Johnson-Cartee, Karen, and Gary Copeland. 1989. "Southern Voters' Reaction to Negative Political Ads in 1986 Election." Journalism Quarterly 66 (4): 888-93, 986.

Kahn, Kim Fridkin, and Patrick Kenney. 1999. "Do Negative Campaigns Mobilize or Suppress Turnout? Clarifying the Relationship between Negativity and Participation." American Political Science Review 93 (4): 877-90.

Kaplan, Martin, Ken Goldstein, and Matthew Hale. 2005. "Local News Coverage of the 2004 Campaigns: An Analysis of Nightly Broadcasts in 11 Markets." Report of the Lear Center Local News Archive, USC Annenberg School, Los Angeles and University of Wisconsin, Madison.

Kunda, Ziva. 1999. Social Cognition: Making Sense of People. Cambridge: MIT Press.

Lau, Richard, and Gerald Pomper. 2000. "Accentuate the Negative? Effectiveness of Negative Campaigning in U.S. Senate Elections." Presented at the annual meeting of the American Political Science Association, Washington.

Lau, Richard, and Gerald Pomper. 2001. "Effects of Negative Campaigning on Turnout in U.S. Senate Elections, 19881998." Journal of Politics 63 (3): 804-19.

Lodge, Milton, and Charles Taber. 2000. "Three Steps Toward a Theory of Motivated Reasoning." In Elements of Reason: Cognition, Choice, and the Bounds of Rationality, ed. Arthur Lupia, Matthew McCubbins, and Samuel Popkin. New York: Cambridge University Press, 183-213.

Marcus, George, W. Russell Neuman, and Michael MacKuen. 2000. Affective Intelligence and Political Judgment. Chicago: University of Chicago Press.

Miller, Warren, and J. Merrill Shanks. 1996. The New American Voter. Cambridge: Harvard University Press.

Neuman, W. Russell, and Michael B. MacKuen, George E. Marcus, Joanne Miller. 1997. "Affective Choice and Rational Choice." Presented at the annual meeting of the American Political Science Association, Washington.

Redlawsk, David. 2002. "Hot Cognition or Cool Consideration? Testing the Effects of Motivated Reasoning on Political Decision Making." Journal of Politics 64 (4): 1021-44.

Rosenstone, Steven, and John Mark Hansen. 1993. Mobilization, Participation, and Democracy in America. New York: Macmillan.

Sherif, Carolyn, and Muzafer Sherif, eds. 1967. Attitude, EgoInvolvement, and Change. New York: Wiley.

Sigelman, Lee, and Mark Kugler. 2003. "Why is Research on the Effects of Negative Campaigning So Inconclusive? Understanding Citizens' Perceptions of Negativity." Journal of Politics 65 (1): 142-60.

Westen, Drew, Pavel Blagov, Keith Harenski, Clint Kilts, and Stephan Hamann. 2006. "Neural Bases of Motivated Reasoning: An fMRI Study of Emotional Constraints on Partisan Political Judgment in the 2004 U.S. Presidential Election." Journal of Cognitive Neuroscience 18 (11): 1947-58. 